\title{
Barriers and facilitators of consumer use of nutrition labels at sit-down restaurant chains
}

\author{
Amy H Auchincloss ${ }^{1, *}$, Candace Young ${ }^{2}$, Andrea L Davis ${ }^{1}$, Sara Wasson ${ }^{1}$, \\ Mariana Chilton ${ }^{1}$ and Vanesa Karamanian ${ }^{1}$ \\ 'Department of Epidemiology and Biostatistics, Drexel University School of Public Health, 1505 Race Street, \\ Philadelphia, PA 19102, USA: ${ }^{2}$ The Food Trust, Philadelphia, PA, USA
}

Submitted 27 June 2012: Final revision received 16 December 2012: Accepted 20 December 2012: First published online 7 February 2013

\begin{abstract}
Objective: Numerous localities have mandated that chain restaurants post nutrition information at the point of purchase. However, some studies suggest that consumers are not highly responsive to menu labelling. The present qualitative study explored influences on full-service restaurant customers' noticing and using menu labelling.

Design: Five focus groups were conducted with thirty-six consumers. A semistructured script elicited barriers and facilitators to using nutrition information by showing excerpts of real menus from full-service chain restaurants.

Setting: Participants were recruited from a full-service restaurant chain in Philadelphia, Pennsylvania, USA, in September 2011.

Subjects: Focus group participants were mostly female, African American, with incomes $<$ \$US 60000 , mean age 36 years and education 14.5 years. At recruitment, 33\% ( $n 12)$ reported changing their order after seeing nutrition information on the menu.

Results: Three themes characterized influences on label use in restaurants: nutrition knowledge, menu design and display, and normative attitudes and behaviours. Barriers to using labels were low prior knowledge of nutrition; displaying nutrition information using codes; low expectations of the nutritional quality of restaurant food; and restaurant discounts, promotions and social influences that overwhelmed interest in nutrition and reinforced disinterest in nutrition. Facilitators were higher prior knowledge of recommended daily intake; spending time reading the menu; having strong prior interest in nutrition/healthy eating; and being with people who reinforced dietary priorities.

Conclusions: Menu labelling use may increase if consumers learn a few key recommended dietary reference values, understand basic energy intake/expenditure scenarios and if chain restaurants present nutrition information in a user-friendly way and promote healthier items.
\end{abstract}

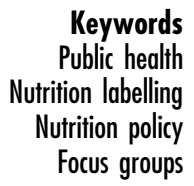

Over the past 25 years, as obesity prevalence has doubled in the USA ${ }^{(1)}$, consumers have increasingly eaten meals away from home ${ }^{(2)}$. In 2008, the New York City Board of Health implemented regulations mandating that chain restaurants display calorie information on fast-food menu boards ${ }^{(3)}$. Many other localities across the USA have implemented similar policies.

Consumer surveys suggest widespread support for nutritional labelling. Survey research found that almost $70 \%$ of consumers favour requiring chain restaurants to post calorie information on restaurant menus ${ }^{(4)}$ and some research has reported that about half of consumers say they will use the information ${ }^{(5)}$. However, while it is too early to assess the full impact of local menu labelling on US consumers, scientific research to date has found modest consumer response to menu labelling. In a few fast-food restaurant intercept studies in the USA, only $50 \%$ of customers saw calorie labels after they were posted on fast-food menu boards and only about $10 \%$ of customers self-reported using the calorie information to decide what to buy ${ }^{(6,7)}$. Recent studies of labelling use among customers at full-service restaurants suggest that a larger proportion of diners used the labels: approximately $75 \%$ of customers saw nutrition labels on printed menus and about one-third reported using the labels; however, most diners are not utilizing labels despite very high calories, fat and sodium in the menu items ${ }^{(8,9)}$. Little is known about why and under what conditions customers notice and use nutritional information at full-service restaurants and whether 
consumers' ability to comprehend the numbers varies by menu display.

Since 2010, Philadelphia, Pennsylvania, USA has required chain restaurants with fifteen or more outlets nationally to post calorie information on menu boards and on printed menus. In addition, on printed menus, restaurants must display calories, saturated fat, trans-fat, sodium and carbohydrates adjacent to each standard menu item and printed menus must include daily dietary reference values for calories and listed nutrients based on a $2000 \mathrm{kcal}$ $(8368 \mathrm{~kJ})$ daily diet ${ }^{(10)}$. Regulations loosely standardized the labelling display but restaurants had some discretion, thus displays varied. Philadelphia is the only jurisdiction in the USA to have mandated such extensive information on printed menus at full-service restaurants (where patrons sit down at a table to order and be served), presenting a unique opportunity for evaluation.

The present exploratory study conducted five focus groups to elicit customers' knowledge, behaviour and attitudes regarding mandatory nutritional labelling at full-service chain restaurants. Given the very limited information available to date, focus groups are an appropriate methodology for exploring barriers and facilitators to using menu labels.

\section{Methodology}

\section{Sample size and participant recruitment}

A convenience sample of focus group participants was recruited in August 2011, during the same date/time as participant recruitment for a companion study, the Drexel Restaurant Study, a consecutive sample of 385 customers who exited two Philadelphia outlets of a national fullservice chain restaurant during evening hours ${ }^{(8)}$. All adult customers exiting the restaurants were invited to participate in the focus groups if they ordered food at the restaurant and anticipated being available to attend one focus group session in Philadelphia in September 2011 during lunchtime or evening, weekdays or weekends. Most tourists and business travellers (over $20 \%$ of the intercept study sample) were unavailable. Eighty-two customers were willing and eligible; of these, thirty-six ( $44 \%$ ) attended one of five focus groups with six to nine persons per session. Participants were compensated \$US 55 cash.

Compared with customers exiting the restaurant who participated in the parent study, the focus groups had: more women (75\% v. 60\%), African Americans (75\% v. 50\%), fewer high-income earners (income $>$ \$US $60000: 17 \% v$. $47 \%$ ), lower education (median years of education: $15 v .16$ ) and slightly more self-reported use of nutrition information at the time of recruitment (33\% v. 26\%). Participants were similar to the diverse, low/mid-income population in Philadelphia although they included a higher proportion of black persons and a lower proportion of Hispanic persons (participants $v$. Census ${ }^{(11)}: 56 \%$ v. $43 \%$ and $6 \% v$. 12\%, respectively).

\section{Data collection methods and procedures}

At the time of recruitment, potential participants provided their name, contact information, age, and whether they saw and used nutrition information at the restaurant. On the day of the focus group session, participants completed a brief pre-focus group questionnaire that asked race/ethnicity, education, income and frequency of dining at full-service and quick-service chain restaurants. Moderators used a semi-structured script that inquired about rationales for food choices at full-service restaurants and customer comprehension and attitudes about nutrition displays on real menus from chain restaurants.

All participants were given excerpts of real menus from five full-service chain restaurants and were asked to discuss what they saw on the menus, what they liked and what they did not like about the menus. At the time of the study, Philadelphia restaurants used two different labelling formats/displays. One label format showed each item with nutrients written out next to corresponding values and units of measurement (' $1030 \mathrm{kcal} / 9 \mathrm{~g}$ sat. fat $/ 1 \mathrm{~g}$ trans fat $/ 95 \mathrm{~g}$ carbs $/ 2300 \mathrm{mg}$ sodium' $(1030 \mathrm{kcal}=4310 \mathrm{~kJ}))$. The second label format showed each item with only the nutrient values separated by slashes or dashes ('1030/9/1/95/2300') and a corresponding key at the bottom of a page ('calories/ saturated fat $(\mathrm{g}) /$ trans fat $(\mathrm{g}) /$ carbs $(\mathrm{g}) /$ sodium (mg)'). Attitudes were solicited from participants in a subset of focus groups regarding dietary reference statements and the restaurant chain's own 'healthier choice' tag/icon; at three out of five groups participants were shown real menu pages that included these features. Dietary reference statements were: 'Recommended limits for a 2000 calorie diet are $20 \mathrm{~g}$ of saturated fat and $2300 \mathrm{mg}$ of sodium. A 2000 calorie daily diet is used as the basis for general nutrition advice, individual calorie needs however, may vary'. Healthier choice tags were icons next to a menu item with a key at the bottom margin that defined the criteria (i.e. 'under $600 \mathrm{kcal}$ ' $(2510 \mathrm{~kJ})$ ).

Median nutrition values on the real menus shown to participants had over one-half of the maximum number of calories per day for most adults, and exceeded daily tolerable limits for sodium and saturated fat ${ }^{(12)}$ (entrées that included a side dish were on average $1100 \mathrm{kcal}$ (4602 kJ), $2500 \mathrm{mg}$ sodium and $21 \mathrm{~g}$ saturated fat ${ }^{(13)}$.

\section{Analysis procedures}

All focus group sessions were audio-recorded and transcribed. After an initial content analysis of the transcripts, five preliminary categories of investigation were identified: attitudes; behaviours; knowledge; attention and priorities; and social and emotional influences. To ensure inter-rater reliability, three of the authors independently reviewed and coded the same index transcript with these five categories in mind (using NVivo9 qualitative data analysis software). Coded text was discussed and coding was adjusted; finally thirty-eight distinct codes were identified. Subsequent transcripts were independently coded by two coders utilizing a 
codebook and this stage preserved text that either or both of the two coders selected. The concordance correlation coefficient $^{(14)}$ for measuring agreement between the two coders was high $(\rho=0 \cdot 97)$, so typically both coders identified similar pieces of text. After investigating the relationships among the codes within the transcripts and between the codes themselves, three broad themes were identified: (i) knowledge; (ii) menu design/display; and (iii) normative attitudes and behaviours. Within each of these themes, primary barriers and facilitators to using nutrition information at the restaurants were identified. With five focus groups, we were able to achieve sufficient saturation (or informational redundancy) ${ }^{(15)}$ on our three primary themes.

Below, to ensure that data are not over-representing a single focus group session or single participant, participants are noted by their focus group number ( $\# 1$ to $\# 5$ ) and identification code. Age is also noted due to wellknown demographic differences in labelling use ${ }^{(16)}$ and is rounded to nearest 10 years to further protect participant confidentiality in the small sample.

Note that the summary of results that follows groups data first by barriers, and then by facilitators. The reader can note divergent responses by contrasting barriers and facilitators for a particular theme (see subheadings 'Barriers - Knowledge' $v$. 'Facilitators - Knowledge', 'Facilitators - Menu design and display' $v$. 'Barriers - Menu design and display', etc).

\section{Results}

\section{Demographics of participants}

Mean age was 36 years old (range: 18-60 years), most participants were female $(75 \%, n 27)$ and identified as black/African American (78\%, $n$ 28), with smaller numbers for white/Caucasian ( $n$ 4), Hispanic/Latino ( $n$ 3) and Asian ( $n$ 1). Participants were approximately evenly distributed into lower, medium and high education groups (high-school and technical school: $n$ 10; 2-year associates degree or some college: $n$ 14; 4-year college or graduate school: $n$ 12). Reported annual incomes were mostly in the mid-income range ( $<$ \$US $30000: n 17$; $>$ \$US $30000-<\$$ US 60 000: $n$ 13; >\$US 60 000: $n$ 6). Thirty-three per cent ( $n$ 12) of participants reported changing their restaurant order in response to seeing nutrition information on the menu. Participants frequently dined at full-service and fast-food chain restaurants (mean 1.3 and 1.4 times weekly, respectively) and reported that they patronized a diverse array of full-service chains.

\section{Themes}

Within the primary themes, several sub-topics were identified as barriers and facilitators to use of nutrition labels (Table 1).

\section{Barriers}

Knowledge

During most of the focus group sessions, most participants indicated they were unfamiliar with dietary reference levels and nutrition information lacked context and meaning for them. One woman who had some college education succinctly described this sentiment for herself and others:

'You see the numbers... You don't know what it means.' (\#1-S, age 30)

A few participants noted that calories on the menu were high but commented that it would not affect what they ordered because they believed a small amount of physical activity would be sufficient to counteract a large

Table 1 Themes that influence individuals' use of nutritional information at sit-down chain restaurants, Philadelphia, PA, USA, September 2011

\begin{tabular}{|c|c|c|}
\hline Theme & Barriers to using labelling information & Facilitators to using labelling information \\
\hline Nutrition knowledge & $\begin{array}{l}\text { Low knowledge of the meaning of nutrients, daily reference } \\
\text { values and what is appropriate for a single meal } \\
\text { Low understanding of what level of physical activity } \\
\text { expenditure is required to balance high energy intake }\end{array}$ & $\begin{array}{l}\text { Seeing nutrition raised initial awareness } \\
\text { (feelings of surprise) } \\
\text { Higher prior knowledge of daily intake needs } \\
\text { and specific nutrients }\end{array}$ \\
\hline $\begin{array}{l}\text { Menu design and } \\
\text { display }\end{array}$ & $\begin{array}{l}\text { Frustration with deciphering nutritional information } \\
\text { especially when key codes are used } \\
\text { Menu layout and pictures do not encourage customers to } \\
\text { purchase healthier items }\end{array}$ & $\begin{array}{l}\text { Support for showing the labels (even if } \\
\text { individuals would not use them) } \\
\text { Restaurant menus that display nutrients } \\
\text { written out with corresponding values and } \\
\text { units of measurement next to each item } \\
\text { Displays that facilitate seeing healthier items } \\
\text { and nutrition reference values }\end{array}$ \\
\hline $\begin{array}{l}\text { Normative attitudes and } \\
\text { behaviours }\end{array}$ & $\begin{array}{l}\text { Low interest in nutrition } \\
\text { Low expectations regarding nutritional quality at the } \\
\text { restaurant } \\
\text { Importance of price, discounts, promotions, along with } \\
\text { social influences that overwhelm interest in nutrition and } \\
\text { reinforce disinterest in nutrition } \\
\text { Belief that nutrition is only important for people who have a } \\
\text { health problem }\end{array}$ & $\begin{array}{l}\text { Spending more time looking at the menu } \\
\text { Strong prior interest in nutrition/healthy } \\
\text { eating and social influences that reinforce } \\
\text { healthy eating norms and healthy diet } \\
\text { priorities } \\
\text { Acknowledgement of a weight problem or a } \\
\text { health problem in self or close family } \\
\text { member }\end{array}$ \\
\hline
\end{tabular}


number of calories. This woman's statement exemplified this misconception:

'By the time you walk to your car or walk home you burned some of those, little bit of calories, off. And then you're, like, "Okay, I can eat it".' (\#1-C, age 40)

\section{Menu design and display}

In four of the five focus groups, participants said that deciphering nutritional information was made harder when 'code' formats were used: slashes or dots next to the item (i.e. '1680/30/2/162/2460') with a descriptive key at the bottom margin (i.e. 'calories/saturated fat $(\mathrm{g}) /$ trans fat (g)/carbs (g)/sodium (mg)'). Some participants confused nutrition numbers with prices. One woman, who selfreported using labels when the nutrient and value were next to each other, succinctly expressed others' frustration:

'Yeah, I wouldn't - If I had to go through the colour coding or, you know, like, go back and forth [look for a key at the bottom], I would ignore it.' ( $\$ 2-\mathrm{T}$, age 30)

A few participants selected their food primarily based on menu photographs and many participants agreed that photographs of menu items looked appealing. At three of the focus groups, a few participants noted that photographs did not feature the healthier menu items and that photographs worked against nutrition information while reinforcing personal taste for high-calorie foods. One woman's statement reflected the views of others:

'If you give me a picture of the [fried] shrimp and you tell me, this [other item] is less calories, even though ... I look and read it, I'll still probably order the [fried] shrimp because that looks good, you know. So, don't tell me about calories and show me the best looking thing on the menu.' ( $\# 4-\mathrm{D}$, age 50 )

\section{Normative attitudes and behaviours}

Many participants said they did not expect restaurant food to be healthy (discussed at all of the focus groups), as exemplified by this woman's statement:

'When I go out, I'm not thinking healthy. If I wanted healthy, I'd cook at home.' (\#5-T, age 60)

Price discounts, promotions and taste were repeatedly noted as strong influences on where and what to eat and overwhelmed thoughts of eating healthily. One woman's remarks on buffet/all-you-can-eat restaurants exemplified statements by others suggesting that large portions, good value and a social atmosphere combined to strengthen disregard of nutrition and relax inhibitions around overeating:

'I got on the good pants with the good waistband. ... When you go to a buffet it's like, because you know you're going to eat, you're like, okay, I got my group, let's get it in. We're going to go eat, and it's on. I know I'm eating worth my money.' ( \#5-K, age 30)

For two male participants, they perceived peer pressure to disregard nutrition; one said:

'We're going out with our friends or something like that... We're going there to eat. We're going there to socialize. We're going there to do whatever. And if I looked at the menu and said, "Oh, well this has two grams of fat, so I'm not going to get this", I would get looks.' (\#3-M, age 30)

In three of the five focus groups, participants were shown menus that listed calories for alcoholic drinks but no one expressed interest in considering labels when ordering alcohol. One woman's opinion was shared by others:

'This is the one area that you don't really think about calories. You might cut back on your food or think about any food, but when you get, you know, a drink, yeah, whatever.' ( $\# 3-\mathrm{D}$, age 50)

A few younger participants justified their disinterest in nutrition information or healthy eating by saying they are healthy. One woman expressed this perspective:

'I don't think that I have any health issues to really think about it. I mean, if I was on the verge of having some type of health issue, I would probably be more aware of what I'm eating. But, I mean, my checkup's been pretty good lately.' (\#3-S, age 20)

Half of participants who self-disclosed that they were a parent reported using labels when ordering for themselves (7/14). A few parents spoke of being dissatisfied with the choices for children on the menu which may facilitate labelling use; however, a number of parents said they would not use the information due to children being picky eaters and/or not appearing to have a weight problem. One parent expressed the view of others when she said:

'It is helpful for some people who want to watch their kids' calories and all of that stuff. For me, it wouldn't make a difference to me because my son, he's skinny; and he's not getting fat right now.' (\#1-S, age 30)

It was not evident from our data that participant disinterest in nutrition was due to infrequently dining out and considering the meal to be a very special occasion or splurge ${ }^{(17)}$. Most participants in our sample frequently ate out (more than twice weekly at full-service chains and fast-food chains) and discussed habitual attitudes and behaviours.

\section{Facilitators}

\section{Knowledge}

Trans-fat, a single digit number, and saturated fat, mostly a double-digit number, were infrequently mentioned and 
when discussed at all, participant statements suggested no understanding of the magnitude of the numbers or what these fats were. Nevertheless, regardless of their prior knowledge, participants throughout all of the focus groups voiced surprise that calories and sodium were in the thousands (units were kilocalories and milligrams, respectively). Despite acknowledging they did not know what 'too much' sodium was, participants noted:

'It's a high number ... That would be a red flag for me.' (\#1-C, age 40)

A woman echoed others' views when she said she was unable to detect high sodium by taste alone:

'Before the sodium was on here [the menu], I used to add it with the pepper and make sure it tasted well but now, looking at the sodium, I'm like "Oh, my God there's already that much in it".' (\#5-M, age 20)

While most participants had low knowledge of nutrients and daily intake needs, in four out of five focus groups, a couple of participants had higher knowledge and could readily interpret the labels. For example, higher-level interpretation was displayed by this woman when she noted:

'These salads don't even look like salads when you look at the calories. I mean, this one salad has almost a full day's worth of calories... 1400 calories. It's not even a salad. They might just as well say chicken and cheese with a side of lettuce.' (\#5-E, age 20)

\section{Menu design and display}

Although only a minority of participants reported using labels, in general, participants were supportive of listing the nutrition on the menus either for themselves:

'It doesn't necessarily change what I'm going to eat all the time, but I do like to see it.' ( $\# 2-\mathrm{H}$, age 30$)$

or for others:

'I think it is helpful because if people have, like high blood pressure or, you know, some type of thing they should know how much sodium, milligrams of sodium is inside the food that they're eating.' (\#3-S, age 20)

Most participants anticipated that if they were going to read menu labels then, compared with the keyed labels, the information was easiest to read/process when the nutrition value and description was next to each item in written words (see Methods for details). One man explained:

'This one, like, actually tells you, like, what it is: 1680 calories, $30 \mathrm{~g}$ of saturated fat. It's easier for you to understand, and, like, it's out there. There's no extra effort needed to, like, read it.' (\#3-J, age 20)

Most participants said they wanted a context for the labels. Dietary reference information was displayed in the margins of some but not all of the real menus shown participants (see Methods for details). However, when displayed, only a few participants noticed it; and even after the facilitator pointed out the display, reference information did not generate much discussion. A number of participants continued to be confused and were unable to successfully interpret the numbers, as exemplified by this woman's statement:

'What does it say? It ain't saying nothing. It's just saying recommended for what, all day? Just for this meal?' (\#4-T, age 50)

Similarly, even though customers stated that they thought 'healthy choice' icons would be beneficial, when they were displayed on the menu they went unnoticed until pointed out by a focus group facilitator. It was difficult for participants to differentiate 'healthy choice' icons from other icons ('signature', 'new', 'spicy', etc.) on menus that were graphically overwhelming.

\section{Normative attitudes and behaviours}

In all of the focus groups, there were a few participants who spoke about taking time to read the menu to find a healthier meal. While many participants suggested that social influences and the restaurant setting relaxed inhibitions around overeating, at two of the focus groups a couple of participants noted that the people around them helped reinforce healthier decisions. One woman said:

'I'm pretty lucky... when we go out, it's, we're all kind of conscious about what we're eating... So, you know, to go and work out for two hours and then go sit down and bust out 2,000 calories in one meal is like, you know, we wouldn't even do it... I usually make a healthier choice just based on that, just based on everybody around me... So that helps my decisions.' (\#2-T, age 30)

A higher proportion of participants who verbally acknowledged a weight problem, a chronic health condition or a close family member with a chronic health condition reported using labels compared with others (45\%, 5/11 v. $28 \%, 7 / 25)$. The following quotes come from two women who exemplified the strong opinions expressed by some:

'I have arthritis ... if I don't lose some weight, eventually, I'm going to have to have a hip transplant. So now it's like really on my mind to try to do better and eat better. So I like ... this menu, because it's [calories] right there under the name. So that just catches my eye.' (\#3-D, age 50)

and

'I take insulin and I have to change - it's really hard and you have no idea... So the menus, when they have the calories on it and everything, it helps me a lot, a whole lot ... we need that in all the restaurants. ... It makes you make different choices 
and everything because I went in there for a particular thing and I totally changed everything around. ( \#2-DG, age 60)

However, there was no consensus and small numbers of people disclosing conditions ( $n$ 11) prevented us from drawing strong conclusions from this finding.

\section{Discussion}

Focus group participants were mostly mid-income, black/African American, frequent restaurant users and were generally supportive of requiring that full-service restaurants display nutrition labels (calories, saturated fat, trans-fat, carbohydrates and sodium). Nevertheless, most participants acknowledged they were not likely to use the information. Recent studies of labelling use among customers at full-service restaurants confirm that labels are being used by only about one-third of restaurant patrons when deciding what to order ${ }^{(8,9)}$ despite very high calories, fat and sodium levels in menu items ${ }^{(13,18)}$.

Our focus group results suggested that barriers to using nutrition information on menus include: low prior knowledge of nutrition; confusion over numbers, particularly when key codes were used to display nutrition information; little time and attention given to reading the menu; low expectations of nutritional quality of restaurant food; and restaurant discounts, promotions and social influences that either overwhelmed interest in nutrition or reinforced disinterest in nutrition. Facilitators that appeared to help promote labelling use were: displays that made nutrition information easier to read; spending time reading the menu; having high prior knowledge of nutrition; strong interest in nutrition/healthy eating; and being with people who reinforced dietary priorities.

Even among customers who are theoretically receptive to using nutrition information, low prior nutrition knowledge may significantly reduce efficacy of using menu labels while dining at a restaurant. In our study, most focus group participants were unaware of their calorie needs or even the $2000 \mathrm{kcal}(8368 \mathrm{~kJ})$ benchmark and many seriously underestimated the amount of physical activity required to compensate for a high-calorie meal. Sodium values on the menus were very high, yet participants indicated even lower knowledge of the upper limit for sodium than for calories (similar to what has been reported by others ${ }^{(19,20)}$ ). Absent a context for the numbers, we speculate that high numbers were unable to promote sufficient concern to motivate changes in purchase decisions ${ }^{(21)}$.

It has been 20 years since the Nutrition Labeling and Education Act, USA was implemented ${ }^{(22)}$, yet research shows that most consumers still do not know the most basic dietary reference values and cannot interpret reference statements when displayed ${ }^{(16,23)}$. Dietary reference statements may need to be re-written at a lower comprehension level. For example, some focus group participants did not appear to understand that statements such as '2000 calorie daily diet is used as the basis... ${ }^{\text {(12) }}$ serve the dual purpose of defining calorie limits and serving as the basis for daily reference values for other nutrients for most adults. Simpler statements such as 'Most adults should eat no more than 2000 calories a day', used in a recent public health campaign $^{(24)}$, may improve understanding.

Educating consumers about dietary reference levels may be critical to increase the utility and comprehension of nutrition information provided in restaurant settings ${ }^{(25)}$. However, knowledge alone is usually insufficient to motivate healthier food choices ${ }^{(26,27)}$. Focus group responses suggested that the combination of unhealthy eating norms, a social atmosphere and environmental cues like price promotions and large portions reduced inhibitions and encouraged overconsumption of food and alcohol in full-service restaurant settings. Other studies support our finding that nutrition often does not rank well against more typical motivators such as taste/preferences and price ${ }^{(26-28)}$ and other research has documented that chain restaurant promotions do not usually feature healthier items ${ }^{(9,29,30)}$.

The present study compared customer attitudes toward two labelling displays currently being used on print menus at chain restaurants in Philadelphia. Focus group responses suggested that key coded displays virtually ensured low use and comprehension of nutrition information. While focus group participants believed that 'healthy choice' icons could help guide choices, the restaurants' actual 'healthy choice' icons were overwhelmed by competing graphics on menus and densely configured layouts, and were not readily noticed. Low consumer tolerance for spending time reading nutrition labels and low nutrition knowledge have led some public health professionals to advocate for nutrition guidance systems that feature simple easy-to-understand graphics rather than numbers ${ }^{(31,32)}$ or a combination of graphics and numbers ${ }^{(33)}$.

\section{Limitations}

We were concerned that sensitization to 'health' and 'labels' may encourage participants to overstate their interest in health and in nutrition labels (health-related or labelling-related desirability bias ${ }^{(34)}$ ), so we removed the word 'health' from recruitment materials and the focus group guide. During focus group discussions, respondents did not overwhelmingly report strong interest in health or in using nutrition labels; nevertheless, we cannot rule out these biases. Our study is limited in its generalizability. Participants were recruited from two locations of a single full-service restaurant chain (although they reported patronizing a diverse array of full-service chains other than the one from which they were recruited), were predominantly female (generally associated with higher nutrition awareness and labelling use $^{(16)}$ ), African American (generally associated with lower labelling use ${ }^{(16)}$ ) and had mid-range education and income (high education and income levels have been 
associated with greater nutrition labelling use $\left.{ }^{(8,16)}\right)$. While results may not be generalizable to all populations, it is nevertheless crucial to understand barriers and facilitators to labelling use among the population subgroup that participated in the study - urban African-American women - due to their high risk for obesity and chronic disease ${ }^{(35)}$.

\section{Conclusions}

Nutrition information assists some consumers in making healthier decisions. However, consumer use of menu labels in full-service restaurants faces significant challenges. Key challenges to effectiveness of menu labels are: (i) nutrition information presented in key codes and highliteracy formats; (ii) nutrition information provided in a context that promotes purchase of unhealthy items and overconsumption; and (iii) customers' lack of knowledge of recommended daily limits for calories, sodium and saturated fat. Use of labelling could be facilitated by: (i) displays presented in easy-to-read formats; (ii) restaurants promoting healthier menu items more consistently; and (iii) educating consumers about dietary reference levels. More public health efforts are needed to demystify nutrition information and to acquaint consumers with basic energy intake/ expenditure scenarios as well as dietary reference levels (upper limits for calories, saturated fat and sodium) that are most important to stemming the obesity epidemic and preventing the onset of chronic disease. Overall, focus group findings shed light on fairly low use of menu labelling reported in previous studies. Results highlight the importance of multi-sector interventions that simultaneously educate consumers, target social norms and alter environments that prompt unhealthy eating ${ }^{(36-38)}$. Menu labelling is still a new public health intervention. More research is needed on visual display, wording, relationship to health literacy and accuracy in applying label information to dietary decision making. Future research should include exploring menu labelling responses after more US restaurant patrons become exposed to menu labels ${ }^{(39)}$ and the impact among different populations.

\section{Acknowledgements}

Sources of finding: The study was funded, in part, by Cooperative Agreement \#1U58DP002626-01 from the Centers for Disease Control and Prevention, US Department of Health and Human Services; and Get Healthy Philly, an initiative of the Philadelphia Department of Public Health. The views expressed in this manuscript do not necessarily reflect the official policies of the Department of Health and Human Services or the Philadelphia Department of Public Health; nor does mention of trade names, commercial practices or organizations imply endorsement by the US Government. Conflict of interest: The authors have no conflict of interest to report. Author contributions: A.H.A. directed all aspects of the study and V.K. was the data collection supervisor. A.H.A., M.C. and C.Y. moderated the focus groups. A.L.D. and S.W. coded the data. A.H.A. and A.L.D. drafted the manuscript. All authors contributed to the design of data collection instruments and revised successive drafts of the manuscript. Acknowledgements: The authors thank all of the individuals who participated in the focus groups and Giridhar Mallya for his comments on the manuscript.

\section{References}

1. National Center for Health Statistics (2011) National Health and Nutrition Examination Survey Data. Hyattsville, MD: US DHHS, CDC.

2. Kant AK \& Graubard BI (2004) Eating out in America, 1987-2000: trends and nutritional correlates. Prev Med 38, 243-249.

3. Farley TA, Caffarelli A, Bassett MT et al. (2009) New York City's fight over calorie labeling. Health Aff (Millwood) 28, w1098-w1109.

4. Bleich SN \& Pollack KM (2010) The public's understanding of daily caloric recommendations and their perceptions of calorie posting in chain restaurants. BMC Public Health 10, 121.

5. Krukowski RA, Harvey-Berino J, Kolodinsky J et al. (2006) Consumers may not use or understand calorie labeling in restaurants. J Am Diet Assoc 106, 917-920.

6. Elbel B, Kersh R, Brescoll VL et al. (2009) Calorie labeling and food choices: a first look at the effects on low-income people in New York City. Health Aff (Millwood) 28, w1110-w1121.

7. Dumanovsky T, Huang CY, Bassett MT et al. (2010) Consumer awareness of fast-food calorie information in New York City after implementation of a menu labeling regulation. Am J Public Health 100, 2520-2525.

8. Auchincloss AH, Mallya G, Loenberg B et al. (2013) Customer responses to mandatory menu labeling at full service chain restaurants. Manuscript submitted to $\mathrm{Am} \mathrm{J}$ Prev Med.

9. Pulos E \& Leng K (2010) Evaluation of a voluntary menulabeling program in full-service restaurants. Am J Public Health 100, 1035-1039.

10. Philadelphia Department of Public Health (2010) Philadelpbia Menu Labeling Ordinance [Code $\$$ 6-102, 6-308]. Philadelphia, PA: PDPH; available at http://www. phila.gov/health/pdfs/MenuLabelinguideFINAL2010-27.pdf

11. US Census Bureau (2010) Census Quick Facts. http:// quickfacts.census.gov/qfd/index.html (accessed December 2011).

12. US Department of Agriculture \& US Department of Health and Human Services (2011) Dietary Guidelines for Americans, 2010, 7th ed. Washington, DC: US Government Printing Office.

13. Auchincloss AH, Loenberg BL, Glanz K et al. (2013) The healthfulness of sit-down chain restaurants: an analysis of restaurant menus. J Nutr Educ Behav (In the Press).

14. Lin LI (1989) A concordance correlation coefficient to evaluate reproducibility. Biometrics 45, 255-268.

15. Brod M, Tesler L \& Christensen T (2009) Qualitative research and content validity: developing best practices based on science and experience. Qual Life Res 18, 1263-1278.

16. Campos S, Doxey J \& Hammond D (2011) Nutrition labels on pre-packaged foods: a systematic review. Public Health Nutr 14, 1496-1506.

17. Ary DV, Toobert D, Wilson W et al. (1986) Patient perspective on factors contributing to nonadherence to diabetes regimen. Diabetes Care 9, 168-172. 
18. Wu HW \& Sturm R (2012) What's on the menu? A review of the energy and nutritional content of US chain restaurant menus. Public Health Nutr (Epublication ahead of print version).

19. Burton S, Creyer EH, Kees J et al. (2006) Attacking the obesity epidemic: the potential health benefits of providing nutrition information in restaurants. Am J Public Health 96 , 1669-1675.

20. Papadakis S, Pipe AL, Moroz IA et al. (2010) Knowledge, attitudes and behaviours related to dietary sodium among 35to 50-year-old Ontario residents. Can J Cardiol 26, e164-e169.

21. Fischhoff B, Brewer NT, Downs JS (editors) (2011) Communicating Risks and Benefits: An Evidence-Based User's Guide. Silver Spring, MD: US DHHS, FDA; available at http://www.fda.gov/downloads/AboutFDA/Reports ManualsForms/Reports/UCM268069.pdf

22. US Food and Drug Administration (1994) Guide to Nutrition Labeling and Education Act (NLEA) Requirements. Silver Spring, MD: FDA, Division of Field Investigations, Office of Regional Operations, Office of Regulatory Affairs.

23. Steenhuis IH \& Vermeer WM (2009) Portion size: review and framework for interventions. Int J Behav Nutr Phys Act 6, 58.

24. New York City Department of Health and Mental Hygiene (2008) Health Department Launches Calorie Education Campaign. Press Release \# 66-08, 6 October 2008. http://www. nyc.gov/html/doh/html/pr2008/pr066-08.shtml (accessed January 2013).

25. Rothman RL, Housam R, Weiss H et al. (2006) Patient understanding of food labels: the role of literacy and numeracy. Am J Prev Med 31, 391-398.

26. O'Dougherty M, Harnack LJ, French SA et al. (2006) Nutrition labeling and value size pricing at fast-food restaurants: a consumer perspective. Am J Health Promot 20, 247-250.

27. Rydell SA, Harnack LJ, Oakes JM et al. (2008) Why eat at fast-food restaurants: reported reasons among frequent consumers. J Am Diet Assoc 108, 2066-2070.

28. Harnack LJ \& French SA (2008) Effect of point-of-purchase calorie labeling on restaurant and cafeteria food choices: a review of the literature. Int J Behav Nutr Phys Act 5, 51.
29. Bellitz S (2012) An analysis of a sit-down chain restaurant menu and its customers: how 'healthy' are menu items and what are customers purchasing? Master's Thesis, Drexel University.

30. Saelens BE, Glanz K, Sallis JF et al. (2007) Nutrition Environment Measures Study in restaurants (NEMS-R): development and evaluation. Am J Prev Med 32, 273-281.

31. Hawley KL, Roberto CA, Bragg MA et al. (2013) The science on front-of-package food labels. Public Health Nutr 16, 430-439.

32. Feunekes GI, Gortemaker IA, Willems AA et al. (2008) Front-of-pack nutrition labelling: testing effectiveness of different nutrition labelling formats front-of-pack in four European countries. Appetite 50, 57-70.

33. Roberto CA, Bragg MA, Seamans MJ et al. (2012) Evaluation of consumer understanding of different front-of-package nutrition labels, 2010-2011. Prev Chronic Dis 9, E149.

34. Hebert JR, Clemow L, Pbert L et al. (1995) Social desirability bias in dietary self-report may compromise the validity of dietary intake measures. Int J Epidemiol 24, 389-398.

35. Wang YF, Beydoun MA, Liang L et al. (2008) Will all Americans become overweight or obese? Estimating the progression and cost of the US obesity epidemic. Obesity (Silver Spring) 16, 2323-2330.

36. Herman CP, Roth DA \& Polivy J (2003) Effects of the presence of others on food intake: a normative interpretation. Psychol Bull 129, 873-886.

37. McFerran B, Dahl DW, Fitzsimons GJ et al. (2010) 'I'll have what she's having': effects of social influence and body type on the food choices of others. J Consum Res 36, 915-929.

38. Burke MA \& Heiland F (2006) The strength of social interactions and obesity among women. In Agent-Based Computational Modelling, pp. 117-137 [FC Billari, T Fent, A Prskawetz et al., editors]. Heidelberg: Physica Verlag.

39. Stein K (2010) A national approach to restaurant menu labeling: the Patient Protection and Affordable Health Care Act, Section 4205. J Am Diet Assoc 110, 1280-1286, $1288-1289$. 